\title{
断层崖崩积楔及贺兰山山前断裂 全新世活动历史
}

\author{
双起东迁一鹀 \\ （国家地震局地质研究所，北京） \\ 廖玉华张维汥李孟釡 \\ （宁夏回族自治区地震局，银川）
}

笔者等 1982 年 7 月对位于贺兰山山前洪积扇断层崖上的探槽剖面进行了观察, 发现探槽 剖面中存在断层崖经几次错动所形成的几期古崩积物. 此后, 我们又对几个地点的古崩积掼 进行了对比. 现将观察结果综合报道如下.

\section{一、基 本 资 料}

石咀山市红果子沟: 有两条断层崖切过明代长城, 走向均为北北东向, 向东倾斜, 崖高 2 米, 坡角 $26^{\circ}$. 探槽揭露的断层走向北 $25^{\circ}-35^{\circ}$ 东, 倾向南东, 倾角 $65^{\circ}-80^{\circ}$. 西部错断点 地层垂直错距>1.95 米, 长城右旋走滑错距 1.45 米, 墙基垂直错距 0.35 米; 东部错断点地层 垂直错距 >2 米, 长城垂直错距 0.95 米, 均为走滑正断层 ${ }^{[1}$. 上述资料一方面说明西部错断点 以水平错动为主, 垂直错距比东部错断点要小得多; 另一方面, 全新世地层垂直错距大于距今 约 400 年前的长城错距, 说明断层曾经经历了多次错动.

在红果子沟的三个探槽中, $\mathrm{Tc}-2$ 比较浅, 只得到了长城墙基错动数据. $\mathrm{Tc}-1$ 和 $\mathrm{Tc}-3$ 剖面中均发育有三期古崩积物(图 $1 \mathrm{a}$ ).

$\mathrm{Tc}-1$ 探槽剖面中 $\mathrm{A}_{1}$ 组为褐红色粗砾石层, 层理不清, 下部发育于次级地堑之中, 与上部 崩积物的界线不明显 (图 1b). 把该崩积楔东段底面投影到断层面上, 可得到其高度. $B_{1}$ 组为 灰褐色小砾石夹黄土状土, 略具与断层同倾向的倾斜层理, 有时小砾石成层分布. $\mathrm{C}_{1}$ 组为灰 褐色砾石层, 有粗大砾石, 层理不清. 其上为近代堆积的黄土状土夹砾石, 厚约 20-30 厘米. $A_{1} 、 B_{1} 、 C_{1}$ 三期古崩积楔高度见表 1 .

$T c-3$ 探槽剖面上亦有三期古崩积物, 其中 $A_{3}$ 为粗大砗石组成的砾石层, 无层理, $\mathrm{B}_{3}$ 组以 黄土状土为主, 夹砾石, $C_{3}$ 组底部为一薄层砾石层, 上部为砾石和黄土状土的混合物, 顶面界线 不甚清楚. 在 $B_{3}$ 和 $C_{3}$ 近断层一端, 紧靠断层上盘发育有一垂直楔状堆积 ( $\mathrm{x}$ ), 由黄土状土组 成, 夹有个别粗大砾石, 它切割了 $C_{3}$ 和 $B_{3}$, 又可能被略具层理的近代堆积所覆盖, 此楼可能是 最近一次断层错动的产物 (图 1c). 三期古崩积楔的高度亦见表 1. 比较表 1 两个断层崖各次 崩积楔高度可知, 东部断层崖崩积楔的高度均大于西部断层崖崩积楔, 而且它们与前述两断层

本文 1983 年 9 月 21 日收到。 

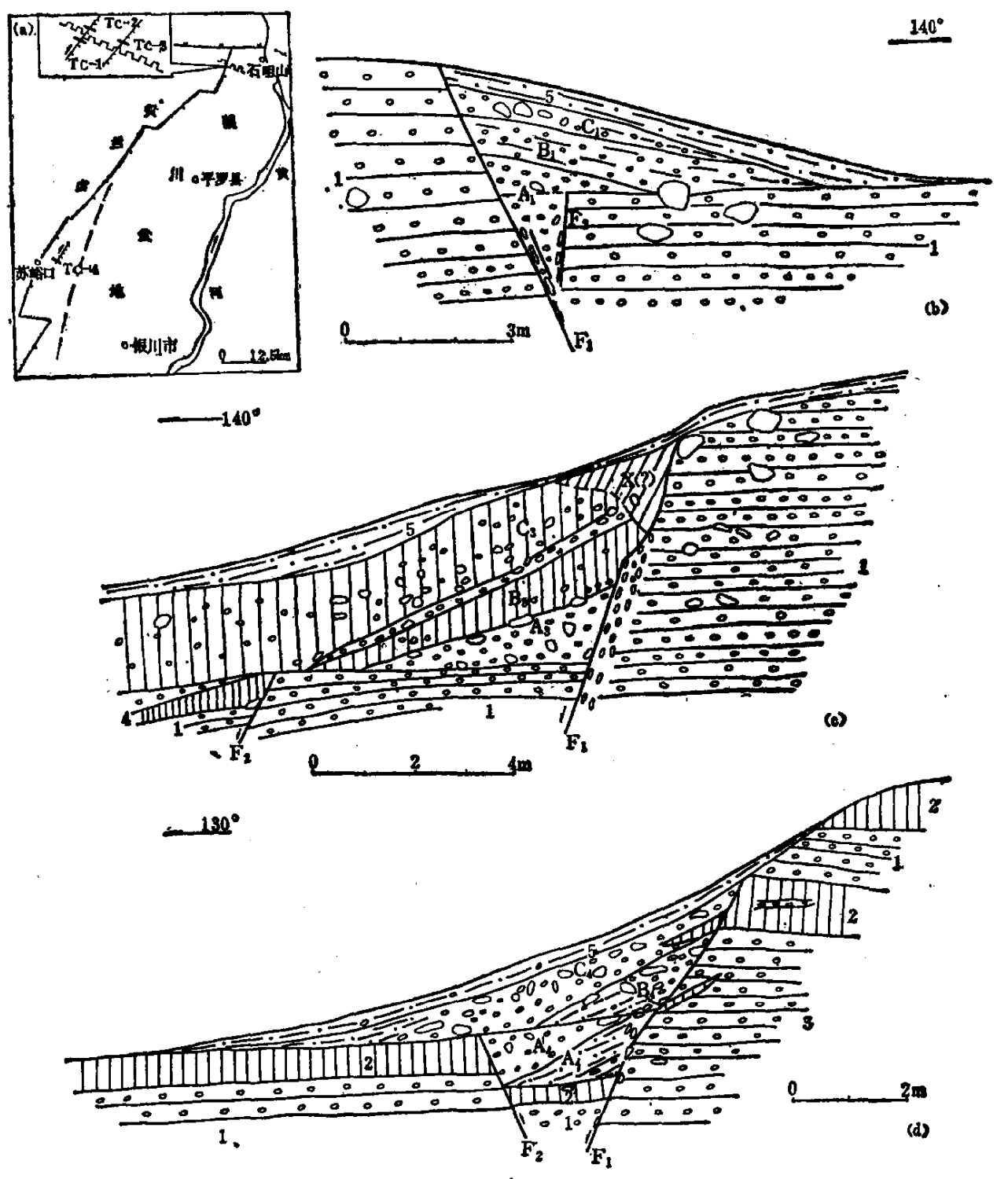

图 1 a. 贺兰山山前断层崖及探槽位置; b. Tc -1 探槽北壁剖面; c. Te-3 探槽南壁剖面; d. Te-4 探槽南壁剖面

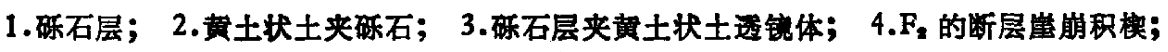
5.近代堆积，黄土状土夹砾石

崖上长城垂直错距的大小相符合.

银川苏峪口: 断层崖切割苏峪口至插旗口等贺兰山山前中段几个巨大的洪积扇，长达 15 公里, 崖高一般 5-6 米, 最高超过 10 米, 自由面可高达 2-3 米. 碎屑坡坡角为 $26^{\circ}$ 左右 ${ }^{[2]}$. 断层崖可成数级错落,具有两种错落形式,一种是错开后的地表面仍保持水平, 另一种是地表 面向断层崖倾斜，它们分别由阶梯状正断层及块体旋转的正断层或铲形断层所控制. 探槽附 近断层崖高 6.7 米,坡角 $26^{\circ}$; 探槽揭露断层走向北 $40^{\circ}$ 东, 倾向南东, 倾角 $70^{\circ}$, 全新世地层 错距约 5 米,断层面上擦痕倾角 $65^{\circ[2]}$, 说明断层亦为右旋走滑正断层,但倾滑分量较大.

Tc-4 探槽南北两壁剖面上亦存在三期古崩积物, $\mathrm{A}_{4}$ 在南壁表现为清楚的三角形楔状体, 由黄土状土夹砾石和薄层砾石层组成, 其上由砾石层 $\left(\mathrm{A}_{4}^{\prime}\right)$ 填满整个小地暂, 它们可能是一次 
表 1 贺兰山山前断层错动事件及崩积籸高度(米)对比表 .

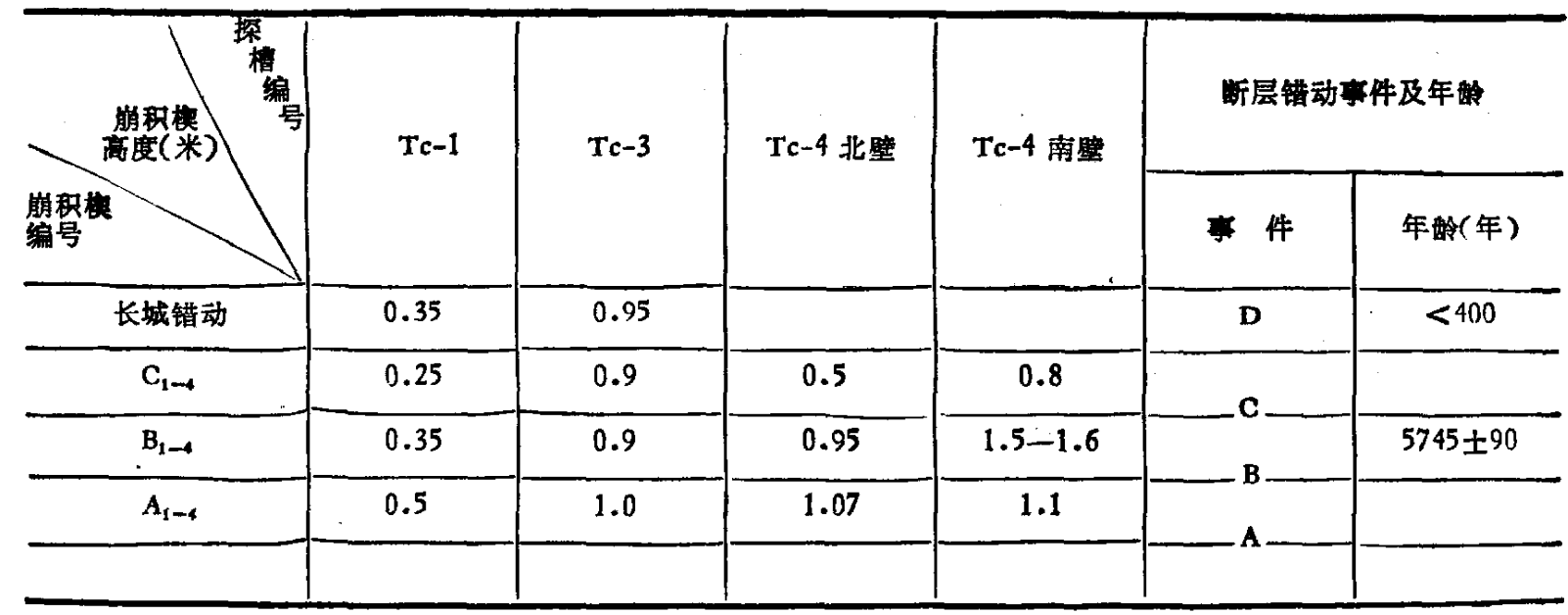

断层错动后的不同阶段的产物. 北壁此期楔状体不清楚,由砾石层 $\left(\mathrm{A}_{4}\right)$ 充满次级地堑. $\mathrm{B}_{4}$ 下 部由砾石层夹少量黄土状土组成,有粗大砾石,但靠近断层一端的上部又有一由较小砾石组成 的三角体，我们暂将二者归在同一崩积栔之中， $\mathrm{B}_{4}$ 覆盖于地堑之上，在北壁可见 $\mathrm{F}_{2}$ 中止于 $\mathrm{B}_{4}$ 底面. $\mathrm{C}_{4}$ 为含土砾石层, 略具向东倾斜的层理, 此层向东转变为含细粒砾石的土层, 层理微微 倾斜. Tc-4 探槽两壁上各期崩积楔高度见表 1. 由表 1 可知, 苏峪口断层崖各期崩积楔高度 与红果子沟东部断层崖相近,大于红果子沟西部断层崖崩积楔的高度.

\section{二、讨 论}

断层崖崩积楔是在断层快速错动形成断层崖后, 自由面上物质不断崩落及断层崖上升盛 地表水片流投运作用在断层崖脚共同形成的堆积物. 容易理解，断层崖多次快速错动会形成 多期崩积楔, 若一次快速错动后, 断层稳定时间较长, 崩积物即可覆盖断层崖自由面, 则崩积躷 近断层一侧的高度就大致与断层崖高度相近或略小。一般认为大地震是断层快速错动的产 物, 因此, 根据崩积楔个数所确定的断层快速错动事件的次数即代表大地震的次数. 若已知研 究区内不同震级地震的地震断层的垂直错距, 则利用古崩积楔高度可大致类比古地震震级,若 能测定崩积物的年龄, 则断层古错动或古地震事件的年龄即可估算. 所以,在进行断层崖研究 时,要注意对断层崖的相关堆积进行研究.

据以上资料, 断层崖崩积楔的基本特征是: 剖面形态为一不等边三角形, 分布于断层崖 下,向断层崖坡向倾斜; 崩积桙近断层一侧的高度大致相当或略小于自由面高度或断层错动幅 度,另一端逐渐尖灭; 崩积物有时不具层理,有时可具与断层崖坡向相同的倾斜层理; 不同期崩 积物成分常有较大差别; 如断层错动后有较长的稳定时间,则崩积楔上表面可有某种程度的土 壤化或风化面。

从前述资料来看,贺兰山山前断裂全新世以来已经历了四次错动,红果子沟东侧断层崖和 苏峪口断层崖垂直位移幅度较大,而红果子沟西侧断层崖垂直错距较小,而且这是三次古错动 和最近一次错动的共同特点. 四次错动事件中的最近一次(事件 D) 错断了建于大约 400 年前 的长城,估计其年龄小于 400 年, 这与断层崖坡角较大、自由面较高的特征相符合. 从洪积层 岩性特征和地貌部位来看,探槽所揭露的洪积物为全新世堆积, 1982 年我们曾在探槽 $T \mathrm{c}-3$ 北 壁 $B_{3}$ 下部层位获得 $C^{14}$ 年龄值 $5745 \pm 90$ 年的资料, 因此, 可以推测 $B$ 事件的年龄值约为 6000 
年左右, $C$ 事件的年龄当在 400-5745 年之间, $A$ 事件的年龄当大于 6000 年, 应为全新世早期 的产物. 由于在洪积物中获得年龄资料十分困难, 目前还未得到更充足的资料来确定每一次 事件的可靠年龄, 但据上述两个年龄资料及有关分析, 推测全新世以来四次断层快速错动或大 地震平均重复间隔约为 $2000-2500$ 年.

关于长城错断事件是否是 1739 年平罗 8 级地震的产物尚有争论, 作者也无意在此加以讨 论, 但自明代长城建成以来, 区内仅仅发生过这一次 7 级以上大地震事件. 若暂时假定二者是 相关事件, 由古崩积楔所确定的三次古错动事件的错动幅度几乎与之有较好的相似性. 因此, 可以推测与三次断层快速错动相应的古地震事件的大小大致与平罗地震相当.

关于断层崖崩积楔与地震关系的研究刚刚开始, 本区断层崖的有关研究正在进行. 作者 希望本文能促进这一方面工作的开展, 并在今后的研究中加以检查和验证.

\section{考文献}

［1] 翏玉华等,地震地质, 4(1982)，2：32-34。

[2] 张维岐等,同上, 4(1982), 2: 77-79. 